\title{
Progress and development of particle jet drilling speed-increasing technology and rock-breaking mechanism for deep well
}

\author{
Tiancheng Fang ${ }^{1} \cdot$ Fushen Ren $^{1} \cdot$ Hanxu Liu ${ }^{1} \cdot$ Yuan Zhang ${ }^{2} \cdot$ Jianxun Cheng ${ }^{1}$
}

Received: 17 August 2021 / Accepted: 21 December 2021 / Published online: 30 December 2021

(c) The Author(s) 2021

\begin{abstract}
Increasing drilling speed and efficiency of hard formation for deep and ultra-deep well is one of the international recognized drilling problems and key technologies to be tackled urgently. Particle jet impact drilling technology is an efficient non-contact rock-breaking method to overcome slow drilling speed, which has great development and application potential in drilling speed-increase of hard formation and deep well. High efficiency drilling technology and rock-breaking speedincrease mechanism in high temperature, high pressure and high hardness formations of deep and ultra-deep wells were mainly focused and keynoted in this paper. With extensive investigation of domestic and foreign literature, the working principle, key technical devices, deep-well-rock mechanical characteristic, unconventional constitutive model and rock-breaking mechanism of particle jet impact drilling technology were analyzed, which proved the feasibility and high efficiency for deep and hard stratum, and also, dynamic failure mechanism of rock needs to be elaborated by constructing the constitutive model with high temperature and pressure. Meanwhile, the major problems to be solved at present and development direction future were summarized, which mainly included: miniaturization of drilling equipment and individualization of drilling bit; optimization of jet parameters and the evaluation method of rock-breaking effect; establishment of mechanical property and unconventional constitutive model of deep-well-rock; rock-breaking mechanism and dynamic response under particle jet coupling impact. The research can help for better understanding of deep-well drilling speed-increasing technology and also promote the development and engineering application of particle jet impact drilling speed-increase theory and equipment.
\end{abstract}

Keywords Deep-well drilling $\cdot$ Particle jet impact $\cdot$ Drilling speed-increase $\cdot$ Key technology $\cdot$ Rock-breaking mechanism . Petroleum engineering

\section{Introduction}

As the strategic resource, oil and gas resources are significant for economic security and sustainable development. With rapid development of international economy and depletion of global shallow oil and gas resources, while carrying out many measures of increasing production and efficiency on the existing wells, the drilling depth is continuously increased to obtain deep resources, so the development of deep oil and gas reservoirs in complex strata has gradually become the focus of oil exploration ( $\mathrm{Li}$ et al. 2020a;

Fushen Ren

renfushen@126.com

1 Northeast Petroleum University, Daqing 163318, Heilongjiang, China

2 Shaanxi Enron Energy Technology Co., Ltd, Xi' an 710000, Shaanxi, China
Abdelghany et al. 2021; Kassem et al. 2021; Radwan and Sen 2021a). Due to the increasing of drilling depth, the exploration and development objects of oil and gas are more complex, and the rock stratum presents high temperature, high pressure and high hardness, the rock-breaking technology of abrasion resistant interval in deep and ultra-deep wells will become an urgent solved technical research direction in the future (Guo and Deng 2021; Radwan and Sen 2021b; Wang et al. 2017a).

With increase of drilling depth and difficulty of rock broken, the traditional operation mostly adopts method of installing drill collar to weight drill string to improve the ROP (Rate of Penetration), however, which will aggravate the bit wear and drilling cost, and the accident is complex with high timeliness. During drilling in hard formation of deep well, not only the drilling speed is slow and the cost is high, the bit wear is serious, but also the serious bit wear, drill pipe buckling deformation and well deviation

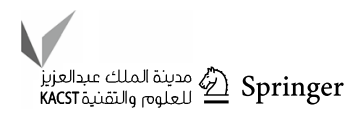


are caused by high WOB (weight of bit), and also the frequent tripping out is caused by high incidence of bottom hole accidents, as shown in Fig. 1. Therefore, the cutting speed and rock-breaking efficiency in deep-well and abrasion resistant formation become key technical problems to restrict the development of deep well drilling ( $\mathrm{Li}$ et al. 2012). At present, the research of efficient rock-breaking methods and equipment has gradually become an important means to solve low rock-breaking efficiency and slow ROP in deep formation. In recent years, scholars have carried out many researches on non-contact efficient rock-breaking methods, mainly including to improve drilling tools and seek new rock-breaking methods (Xu et al. 2018). Due to the limitations of high power consumption, long distance transmission of cable, electromagnetic interference in the application process, high-efficiency rock-breaking methods such as plasma drilling, hot melt drilling, microwave drilling and laser drilling still need to carry out technological breakthrough and innovation (Zhu et al. 2020; Tang and Zhu 2018). The research progress of high-pressure jet technology and particle impact drilling technology is rapid, and the laboratory and field tests is realizing, which has the wide application prospect (Zhao et al. 2014).

For particle jet impact drilling speed-increasing technology, previous studies mostly focused on the overview of efficient rock-breaking methods and system devices, and few studies on the failure mechanism and the constitutive model with high temperature and high pressure of particle jet impact drilling. The innovation is to put forward the

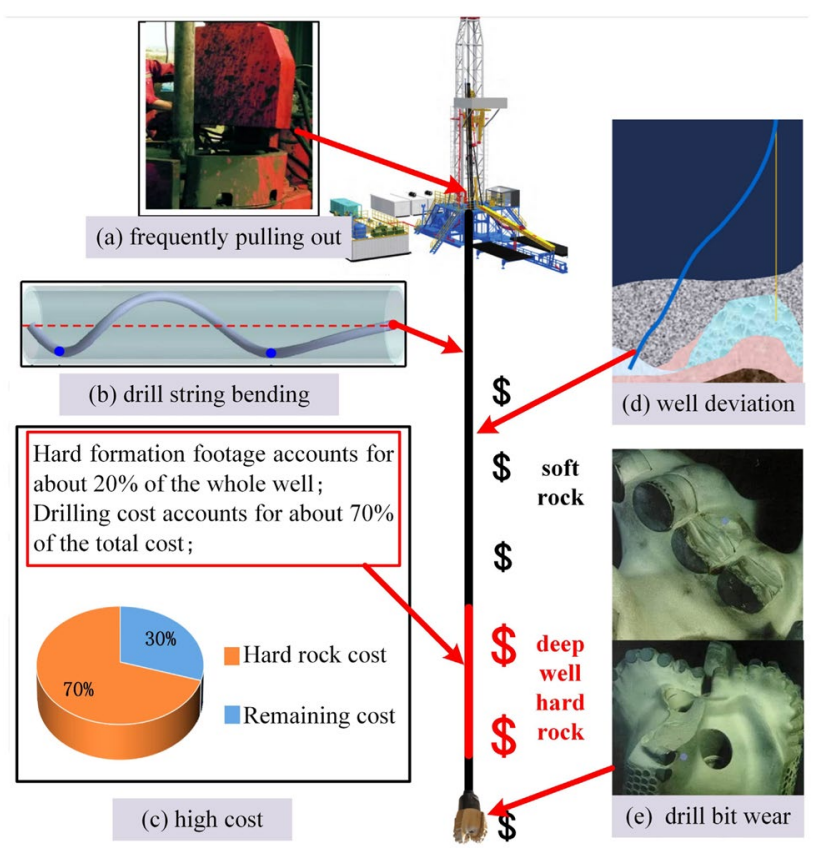

Fig. 1 The problems in hard formation during deep well drilling process necessity of drilling increasing speed and efficiency in hard formation according to the current situation of deep and ultra-deep well drilling, on the basis, summarize the devices and existing problems of particle jet impact drilling system, and put forward the requirements of miniaturization design and evaluation theory of rock-breaking effect. Meanwhile, the rock constitutive model under high temperature and high pressure environment is the premise to reveal rock-breaking mechanism, as well, combination rock-breaking theories are proposed to explain damage evolution mechanism and nonlinear response of particle jet impact drilling.

Therefore, this paper focuses on the rock-breaking mechanism and speed-increasing technology of deep-well and hard formation with condition of "high temperature, high pressure and high stress", the working principle, key technology, research progress and rock breaking mechanism of particle jet impact drilling technology are summarized and researched, and the existent problems and development directions of particle jet impact drilling. The technical route and analytical process is shown in Fig. 2. Firstly, the deep complex oil and gas resources status and drilling distribution are investigated. Then, the key technologies and test devices of particle impact drilling are summarized. Right after, the mechanical properties and unconventional constitutive model with high temperature and high pressure environment of deep rock are studied. On the basis, the rockbreaking mechanism and nonlinear response under particle jet impact is further revealed. Finally, the main problems to be solved and the future development direction are proposed. The finding of this study is of great significance for the development and application of particle jet impact rockbreaking technology.

\section{Deep oil and gas resources status}

According to the dynamic evaluation of oil and gas resources in China ( $\mathrm{Li}$ et al. 2020a), the amount of deep and ultradeep oil resources in land oil and gas resources is about $763 \times 10^{8} \mathrm{t}$, accounting for about $35 \%$ of total oil and gas resources. The resources of deep and ultra-deep natural gas are about $49.7 \times 10^{12} \mathrm{~m}^{3}$, accounting for about $55 \%$ of total natural gas resources. Meanwhile, most of the remaining oil and gas resources in old oilfield also exist in the deep and hard formation, so oil and gas reservoir in deep-well have characteristics of the largest amount of onshore remaining resources, the largest development potential and the most drilling challenges. At present, deep and ultra-deep oil and gas are generally in stage of great discovery and development in China and also others (Jia et al. 2016), the deep and ultra-deep oil and gas fields discovered in China are characterized by large scale and rich resources; however, they are also faced with drilling problems such as buried depth and 
Fig. 2 The technical route and analytical process progress and development of particle jet drilling speed-increasing technology and rock-breaking mechanism

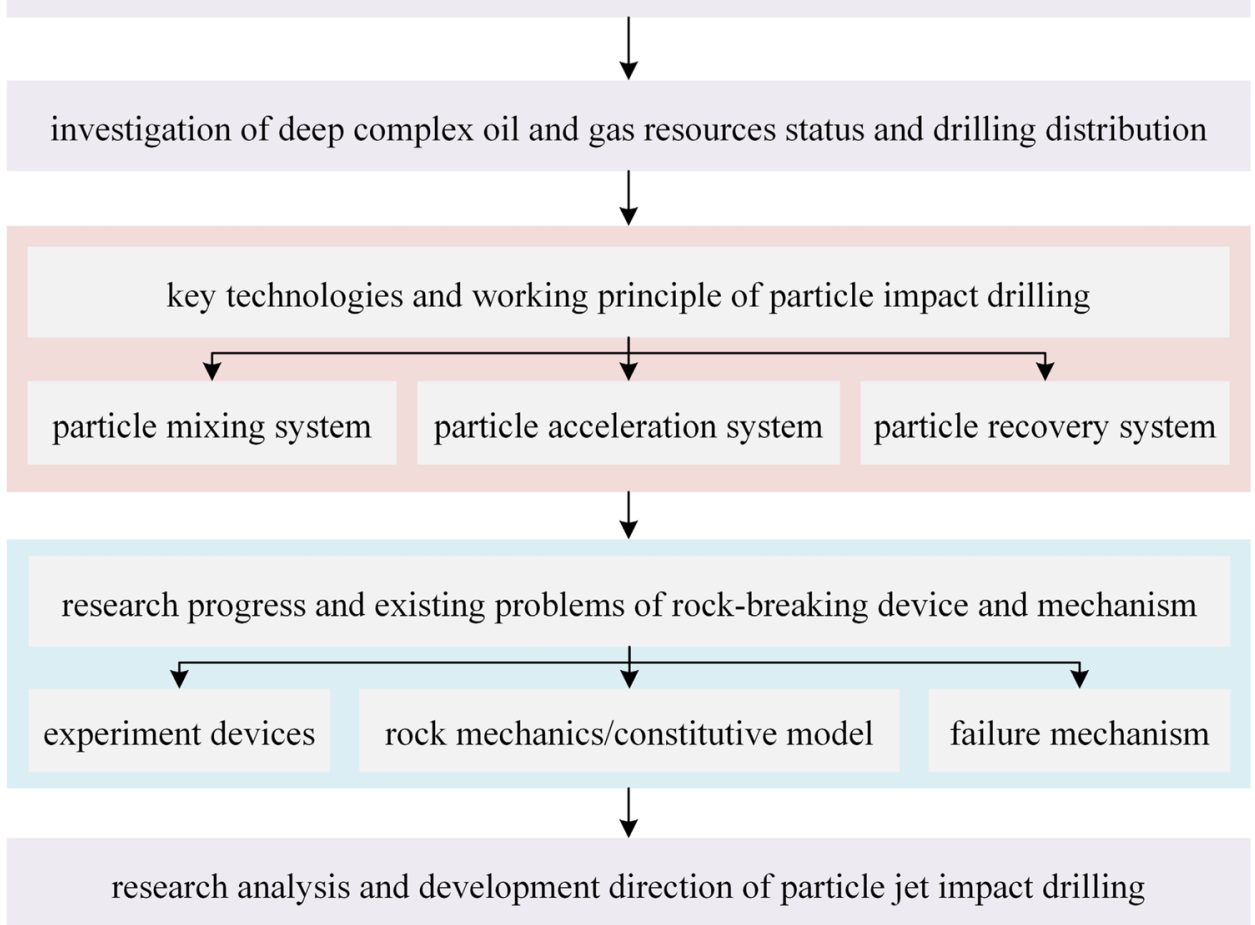

high pressure (Su et al. 2020). The average depth of deep and ultra-deep wells is about $5540 \mathrm{~m}$ and $6750 \mathrm{~m}$ in 2019, the drilling depth will reach $8588 \mathrm{~m}$ (Well Shunbeiying-1) and $8882 \mathrm{~m}$ (Well Luntan-1). The development history of deep and ultra-deep wells in China is shown in Fig. 3.

The world's deep well drilling technology developed in the 1930s, mainly focusing on drilling rigs, drill bits, downhole power tools and mud drilling fluids. The first deep well, ultra-deep well and extra-deep well in the world are $4573 \mathrm{~m}$, $6225 \mathrm{~m}$ and $9159 \mathrm{~m}$, all completed by the United States. In
1984, the drilling depth of the former Soviet Union reached a record with $12200 \mathrm{~m}$, and the second drilling depth reached even $12,869 \mathrm{~m}$. At present, the world's deepest oil drilling record is the depth of 15,000 $\mathrm{m}$ in Odoputu oilfield (Yang et al. 2021).

With further development of oilfield exploitation, more complex geological conditions such as high temperature, high pressure and high hardness will be faced in drilling process. The deep and ultra-deep well drilling technology will develop towards high efficiency, automation, intelligence
Fig. 3 The development history of deep and ultra-deep wells in China

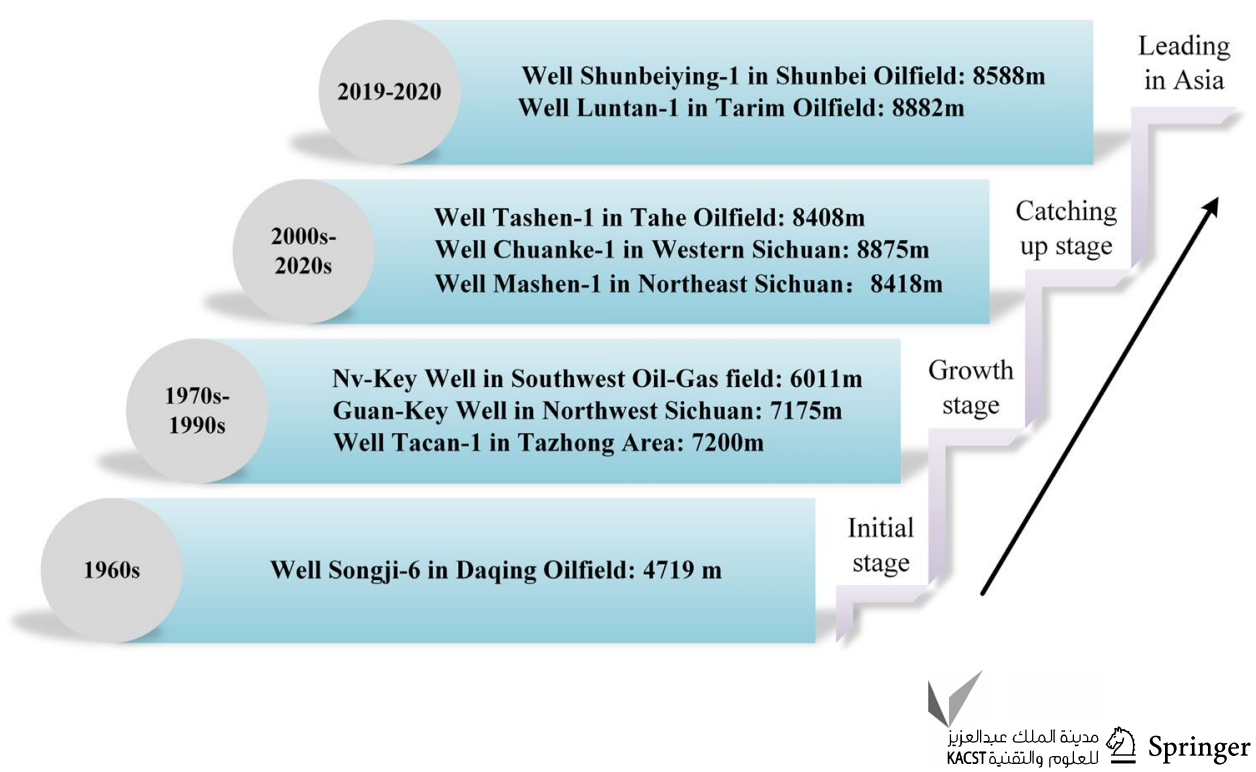


and pilot technology, especially focusing on low cost and high drilling speed, green and environmental protection in the future.

\section{Working principle and key technology}

\section{Working principle}

Particle jet impact drilling technology is a high efficient noncontact rock-breaking means, which break rock mainly by subsonic particles impact and supplemented by high-velocity water and drill bit. As shown in Fig. 4, the working principle is that a certain proportion of steel particles is added into drilling fluid, and the multi-phase flows can be formed subsonic particle jet with accelerate through special nozzle (Ren et al. 2019; Zhang et al. 2009). High-velocity particle jet will break rock surface to form pressure relief groove, which can release compaction stress of deep rock, and reduce rock strength. The rock with broken groove would be cut rapidly under the grinding action of the bit teeth.

When the high-velocity particles impact on rock surface, the exceedingly large instantaneous impact stress will be produced in very small contact area. When particle velocity reach a certain value (called critical velocity of rock-breaking), the instantaneous impact stress will exceed compressive strength of hard rock, and the tensile stress and shear stress will occur around the boundary of contact area. When tensile stress or shear stress formed by impact exceeds the tensile or shear strength of rock, respectively, many cracks or macroscopic failure will be formed inside rock (Ren et al. 2019). Concurrently, the damaged rock would continue to be broken with action of waterjet and rotary grinding of bit teeth, and the generated cuttings and particles can be carried to the separation equipment by waterjet to separate the particles and cuttings, so as to realize the recycling of steel particles.

\section{Key technology of particle jet impact drilling}

\section{Particle mixing system}

For particle jet impact drilling, how to realize the uniform and continuous mixing of steel particles and drilling fluid is the key technology to achieve efficient rock-breaking. At present, according to the principle of particles mixing with fluid, it mainly includes two types: negative pressure injection and mechanical conveying. And mechanical conveying includes screw conveying, rotary vane conveying and plunger conveying, as shown in Fig. 5. The development of particle mixing device has been successively with methods of negative pressure injection, screw conveying, and the tests were also carried out (Thomas 2007; Rach 2007). Such devices can realize the rapid injection of particles, but there are some shortcomings, such as difficult control of particle mixing ratio, and difficult sealing. After that, rotary vane conveying and plunger conveying devices were developed and tested (Li et al. 2014; Xu et al. 2013), which can improve the system stability and accuracy to a certain extent. However, there are also reliability problems due to the existence of moving parts and dynamic seals.

In drilling process, due to the high pressure characteristics of drilling fluid, whether particles can be mixed with high pressure fluid evenly, continuously and stably determines the acceleration effect of particles and rock-breaking

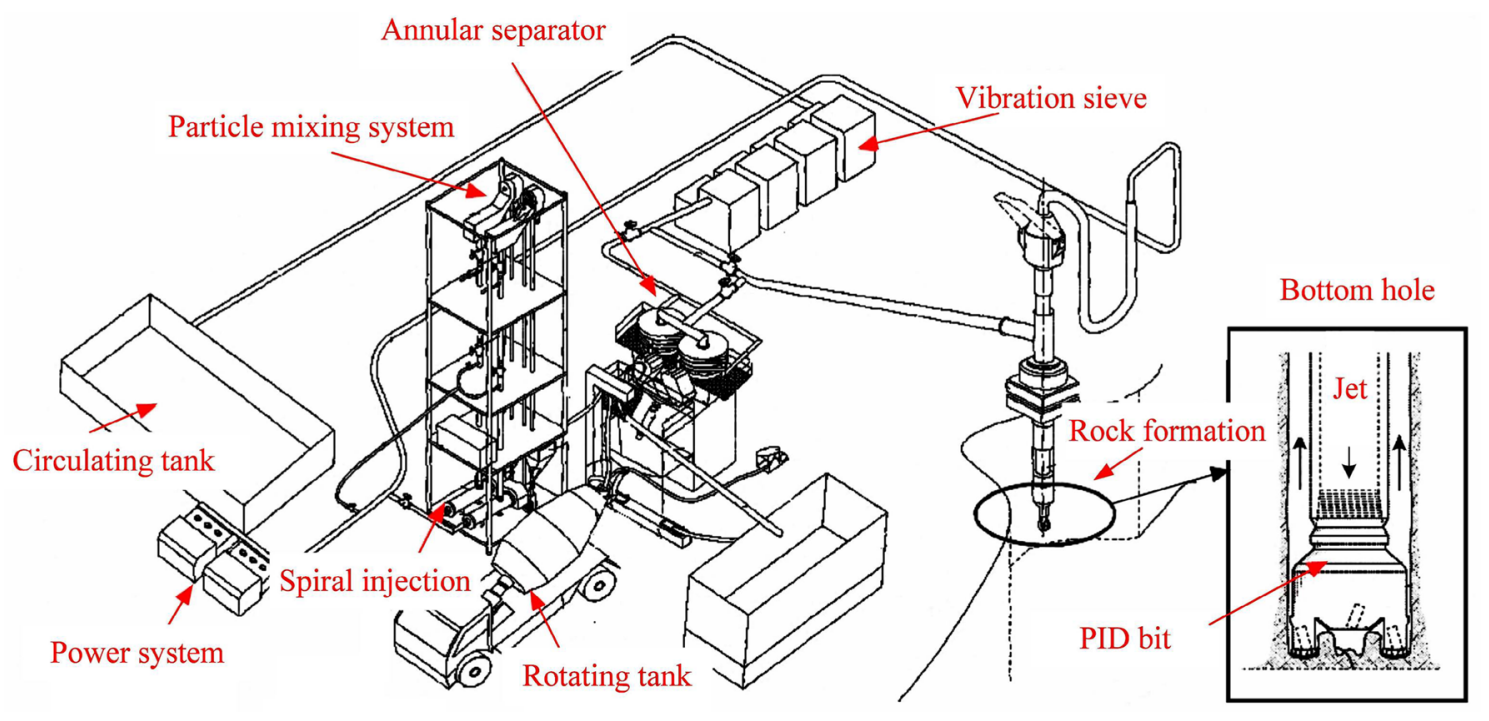

Fig. 4 Process of particle jet impact drilling technology (Zhang et al. 2009)

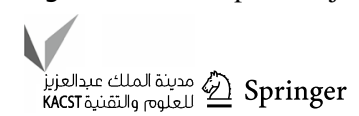




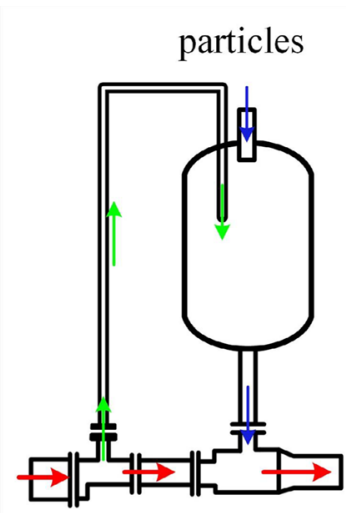

(a) Negative pressure
injection

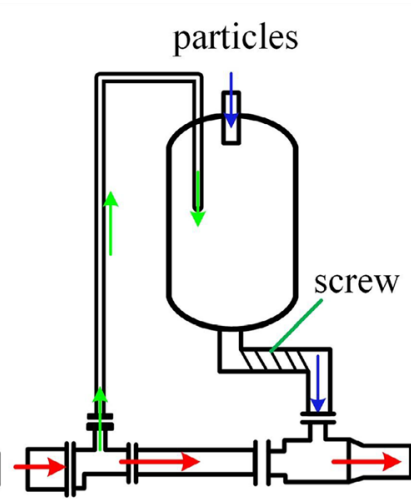

(b) screw conveying

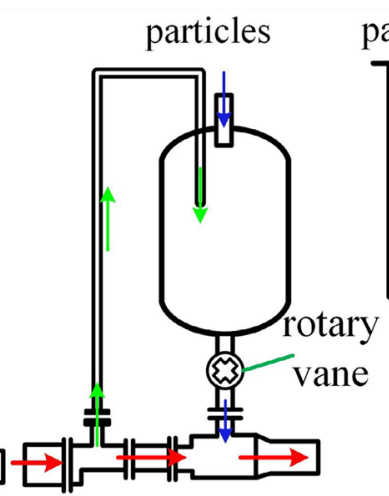

(c) rotary vane conveying

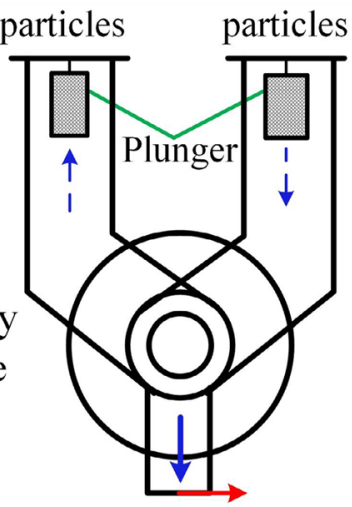

(d) plunger conveying

Fig. 5 Mixed mode of particles and slurry

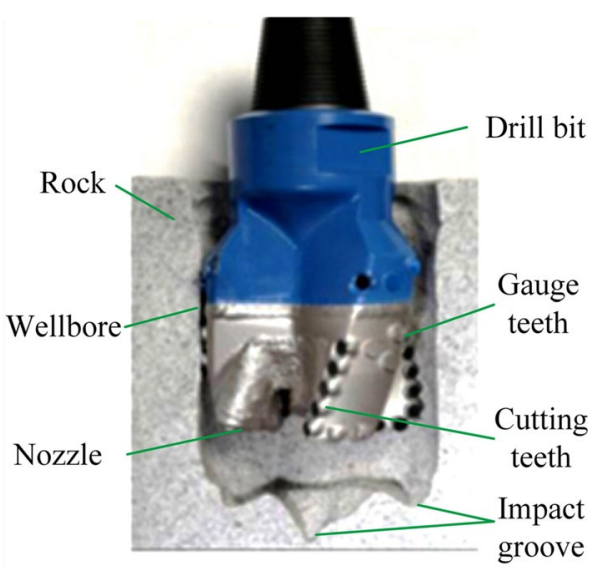

Fig. 6 Particle impact bit structure

velocity. Simultaneously, it has very high requirements for sealing and working reliability of device.

\section{Particle acceleration system}

When steel particles are mixed with drilling fluid, it will go through the acceleration stage of drill string with acceleration action of drilling fluid, until particle velocity reaches the same as fluid velocity. However, to meet the requirements of rock breaking, higher particle jet impact kinetic energy is required; therefore, when the two-phase fluid reaches drilling bit, it is necessary to develop the special bit to obtain subsonic particle jet. Concurrently, the special bit not only has the accelerating function of particles and fluid, but also cutting rock and maintaining borehole diameter, as shown in Fig. 6. The particle impact drilling (PID) bits suited for different sizes of wells has been developed, which is mainly composed of accelerating nozzle, diameter maintaining teeth, cutting teeth and bit body (Thomas 2007). The distribution, number and accelerating flow field of nozzles for PID bit were also developed and researched (Zhao 2016; Ren et al. 2020; Wang 2020). At present, the developed PID bit can basically meet the kinetic energy demand for rockbreaking; however, researches on the optimization of nozzle distribution under rotating condition still need to be further carried out.

The acceleration process of particles includes the acceleration in drilling string and PID bit. Therefore, the particle acceleration system determines impact kinetic energy involved in rock-breaking process, which directly affects drilling speed and rock-breaking efficiency with particle impact.

\section{Particle recovery system}

The main function of particle recovery system is to treat return multi-phase fluid, and to separate particles with rock debris and drilling fluid, and recycle the particles. The process of particle recovery and separation is shown in Fig. 7. At present, the main method is to recycle the effective particles by vibrating screen, magnetic separation and ring separation. And the rotating tank is also adopted to prevent binding effect of particles, and to ensure the reliability of particle recovery system (Zhou et al. 2014). The particle recovery device currently can realize the separation of particles with cuttings, and the reuse of steel particles, but there are still problems of too large volume and high cost.

Because the volume of steel particles is relatively small, and the strength of particles is much higher than that of rock, most particles can still be recycled after use. Therefore, how to realize the separation, recovery and storage of effective particles in the returned multi-phase fluid is an important way to realize resource reuse and save drilling cost. 
Fig. 7 The recovery and separation process of particles

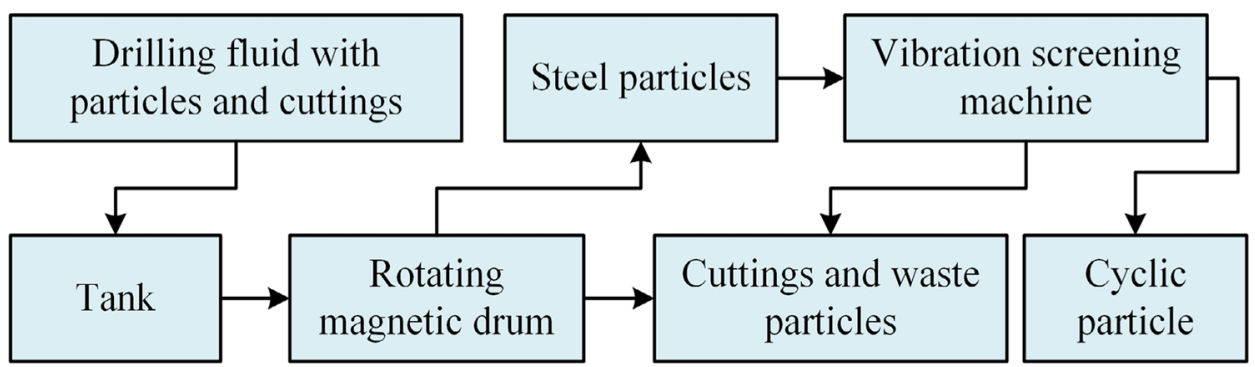

\section{Research progress of rock-breaking device and mechanism}

\section{Particle jet impact drilling device}

In order to achieve rapid drilling in deep and hardness formation, the concept of particle impact drilling was put forward inspired by projectile impact, and the Particle Drilling Technologies, Inc., USA, was established. From 2005 to 2009 , three generations of particle impact drilling devices have been successfully developed, and many laboratory tests and field tests had been carried out (Fig. 8a), and the results proved that particle impact drilling technology can save drilling cost and drilling time, and increase drilling speed by $2 \sim 4$ times (Zhao et al. 2014). Since 2009 , the company has successively developed bit models suitable for all drilling well in USA (Fig. 8b), and the technology of borehole damage, coring were also studied (Tibbitts et al. 2007; Tibbitts 2008). Thereafter, Kovalyov et al. proposed a structural scheme of recycling particles in drilling bit, so as to improve drilling speed (Kovalyov et al. 2015), which would promote the development of self-circulation particle jet impact drilling technology. However, the research on this technology is still in stage of theoretical research.

Domestic scholars began to study particle impact drilling technology in 2008. Wu et al. carried out particle impact rock-breaking experiment by using air cannon, and combined with numerical simulation of double particles impact rock, which proved the high efficiency of rock-breaking ( $\mathrm{Wu}$ et al. 2009). Xu et al. have carried out research on particle classification device and recovery system, and successfully carried out field experiment in Longgang gas field of
Fig. 8 Field test of particle impact drilling and drill bit at abroad

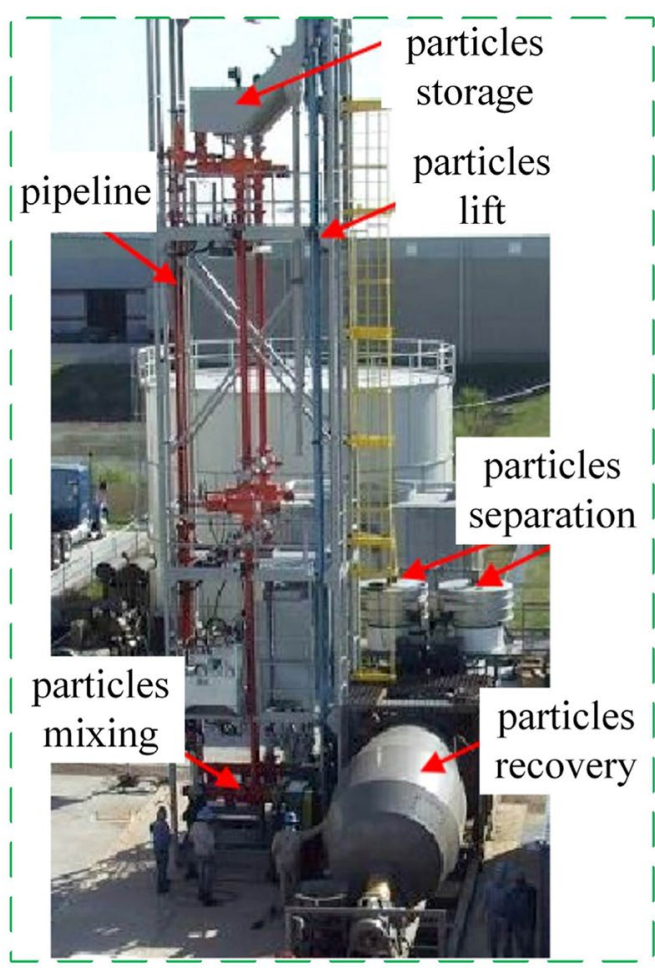

(a) Particle impact drilling test

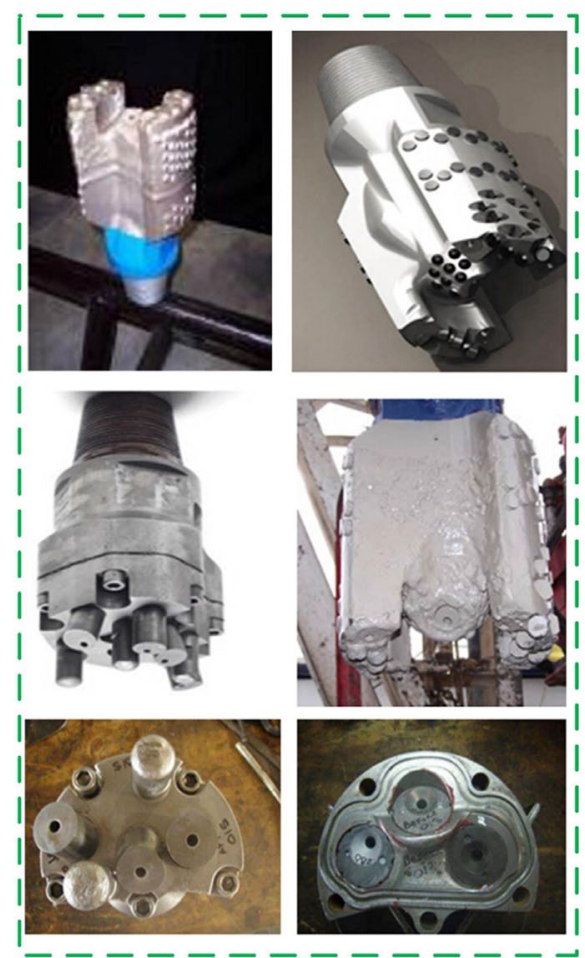

(b) Particle impact bit 


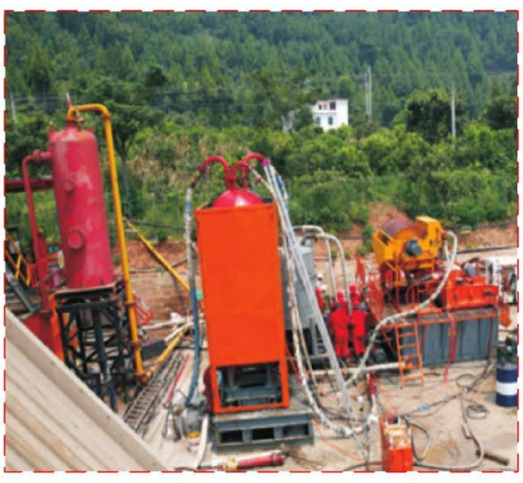

(a) Field test for particle impact drilling

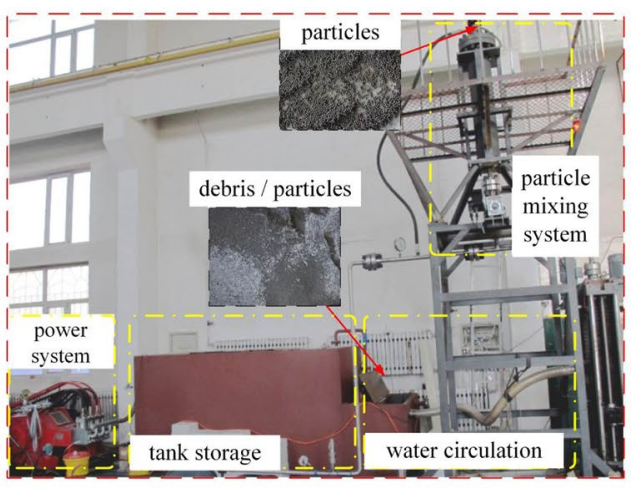

(b) Rock-Breaking experiment with bit rotation

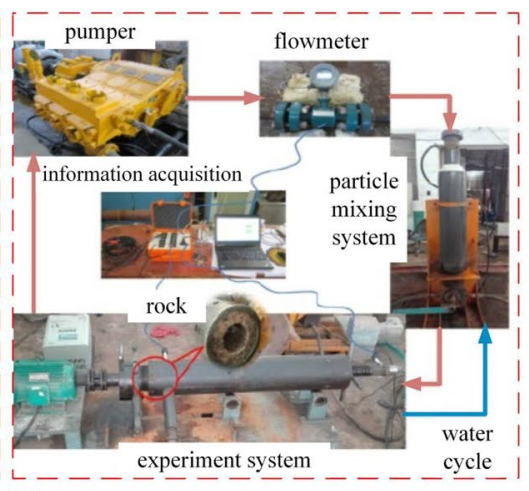

(c) Confining pressure simulation experiment

Fig. 9 Domestic research on particle impact rock-breaking device

Sichuan Basin (Fig. 9a). The rock drilling speed has been increased by more than $90 \%$, indicating that this technology has broad application prospects in improving drilling speed (Zhao et al. 2014; Xu et al. 2012). Ren et al. developed the experimental device of particle jet impact rock-breaking (Fig. 9b), and optimization analysis of rock-breaking parameters was carried out with simulation and experiment (Cheng et al. 2018). Wang et al. analyzed the influence of volume fraction, particle diameter, angle on rock-breaking effect based on particle jet impact rock-breaking experiment (Fig. 9c) (Wang et al. 2017b).

Laboratory experiments and field tests on particle jet impact rock breaking have been carried out at home and abroad, which prove the feasibility and efficiency of particle jet impact drilling technology in deep and hard formation. The above researches would promote the drilling technology from theoretical research to field application. However, at present, the devices development is still mainly based on indoor tests, and there are also some problems, such as large device volume, high application cost and single size of drilling bit. Due to the particularity of application environment (high temperature, high pressure, high hardness, deep formation), the development direction of particle impact drilling technology should be miniaturization of ground devices, accuracy of control system, personalization of drilling bit, self-circulation of particles.

\section{Rock mechanics and unconventional constitutive model of deep-well}

Because particle jet impact drilling technology is mainly aimed at hard rock in deep and ultra-deep well, the depth generally exceeds $4000 \mathrm{~m}$, the rock hardness is about $2000 \sim 5000 \mathrm{MPa}$, and its compressive strength can reach $180 \mathrm{MPa}$, which leads to serious wear, slow drilling and serious tripping (Zhang et al. 2015). With environment at stage of high pressure, high temperature and high stress, the failure of deep-well rock will change from elastic brittle to ductile, even creep characteristics. Therefore, the existing fracture theory based on linear elasticity and Hooke law is no longer suitable for deep-well rock fracture. To investigate mechanical properties of rock and establish constitutive model of rock under coupling action of temperature-pressure (temperature-pressure-seepage) is the key to research rock fracture mechanics in deep wells, and also the premise to reveal rock-breaking mechanism.

The research on rock mechanical properties mainly includes macro analysis (stress, strain, strength) and micro analysis (defects, cracks, deformation). The main way to explore rock mechanical properties is with laboratory tests, and also logging in drilling process (Radwan et al. 2021; Radwan and Sen 2021c). Xi et al. studied the thermal elasticity of granite with temperature under hydrostatic pressure, and analyzed the change of elastic modulus and Poisson's ratio with temperature (Xi and Zhao 2010), shown in Fig. 10a; Yao et al. conducted mechanical test on mudstone based on full-automatic triaxial rheological instrument, and the fracture mode is large plastic compression and lateral ductility deformation, mainly showing brittle shear failure (Yao et al. 2018). In the construction of viscoelastic plastic model, improved D-C constitutive model and damage rheological model were proposed successively to analyze the brittle-plastic-ductile transition process as shown in Fig. 10b (Perzyna 1966; Jiang et al. 2020). Compared with above constitutive models, the failure mode of deep rock does not conform to Mohr-Coulomb criterion; the viscoelastic plastic model can describe the attenuation and rheological deformation under load, and has good application; the thermodynamic viscoelastic model can truly reflect the three-dimensional constitutive relationship of rock damage; however, they all need to be carried out intensively in the subsequent study.

At present, these researches on strength and deformation characteristics of deep rock mechanics are limited to

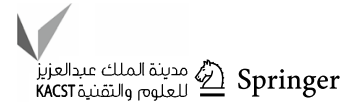




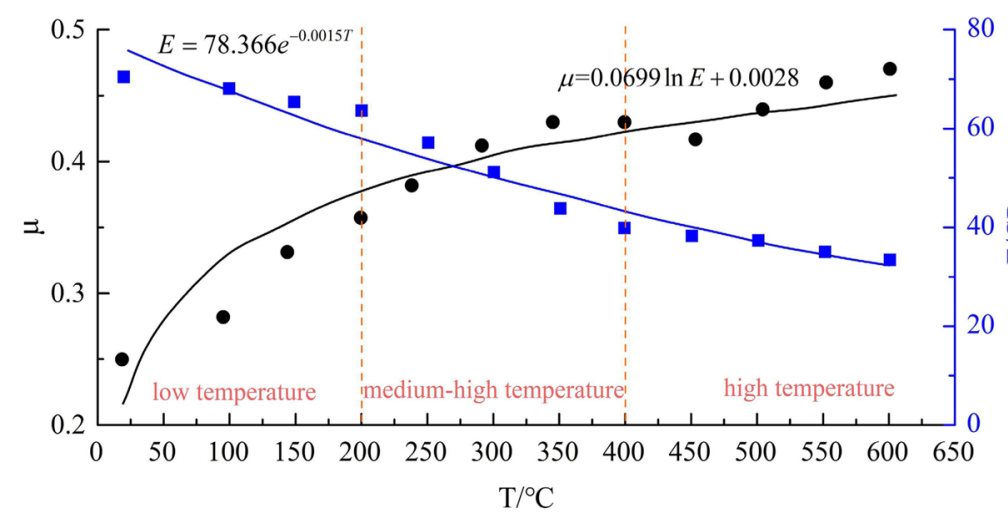

(a) Effect of temperature on mechanical properties of rock

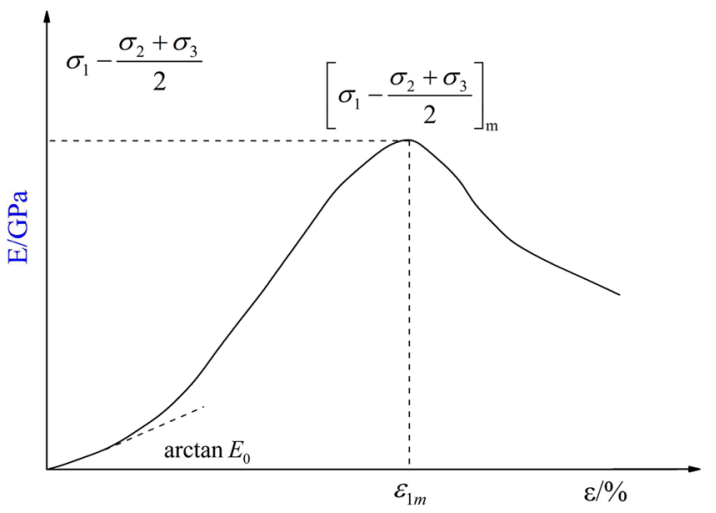

(b) improved D-C constitutive model

Fig. 10 Domestic research on particle impact rock-breaking device

simulation test or conventional test. Because deep-well rock is of high temperature and high pressure environment, not only the strength and strain are affected by confining pressure, but also elastic model will change with depth. As well, hydraulic impact will cause the increase of crevice pressure. Therefore, it is necessary to combine logging data, or fidelity coring technology, to explore mechanical properties of deep well rock, and then construct the constitutive model of elastoplastic mechanics.

\section{Rock-breaking mechanism of particle jet impact}

The jet impact rock-breaking theory can be summarized as tension-wedge theory, core-splitting theory, stress wave theory and cavitation theory, and the vibration rock-breaking theory includes resonance theory, and energy conservation theory. In rock-breaking process, the stress field, energy field and discontinuous deformation of rock are unknown and invisible, and the rock-breaking mechanism with particlewaterjet-bit teeth coupling involved nonlinear dynamic failure under multi-field and multi-phase. Therefore, the energy accumulation, stress wave propagation, rock micro-vibration and resonance of rock need to be investigated, and further revealing the failure mechanism and dynamic response is the key research in deep drilling mechanics.

The micro-vibration and resonant rock-breaking is mainly through adding resonant excitation, and when excitation frequency is equal to resonant frequency of rock, the vibration displacement of rock will reach peak value, that is, resonance failure effect (Tian et al. 2016; Li et al. 2020b; Zhu and Liu 2018). For stress wave rock-breaking, it is considered that, impact kinetic energy will expand inside of rock in form of stress wave, resulting in rock damage (Liu et al. 2016; Huang et al. 2019). With high-frequency impact of particles, the damage will accumulate continuously, which leads to the development and connection of fractures, and finally crush. For the joint rock-breaking theory, it is mainly considered, the particles impact and the cutting of drill teeth will cause rock cracks and fragmentation, and the jet would cause the cracks to form water-wedge effect, which reduces the failure strength and finally crush (Wang et al. 2016). In field of particle jet impact rock-breaking, further researches were also needed to confirm the feasibility of vibration rockbreaking theory and stress wave rock-breaking theory. And, the joint rock-breaking theory has been applied in jet impact rock breaking; however, its applicability in field of particle jet rock-breaking needs to be further investigated.

For rock-breaking of energy conservation theory, impact system and rock are regarded as a stable system, and the release of impact kinetic energy can all transformed into kinetic energy of rock debris and heat energy (Liu et al. 2017), and the transformation process is shown in Fig. 11. In the previous research, taking single particle as research object, the energy absorption rate (the ratio of kinetic energy difference before and after particle impact to total energy of the system) was used to reflect rock-breaking effect, and the jet parameters were also optimized (Ren et al. 2017). Besides, the factors affecting rock failure morphology have been analyzed with the breaking energy theory, and a brittleness evaluation method was proposed (Zhao and Gou 2020). It is feasible to use energy absorption efficiency to evaluate rock-breaking effect, but the error lies in the neglect of internal energy and the interaction between particles and jet.

For stress failure theory, high frequency impact of particles will cause damage accumulation, crack expansion, and finally crush. Geng et al. analyzed the rock breaking process and the difference between tensile strength and compressive strength (Geng et al. 2017). Jiang et al. established high-pressure jet impact rock-breaking model and revealed that the damage of rock is the joint action of shear and tension (Jiang et al. 2020). Abdideh et al. based on stress field analysis studied the effect on selection of 


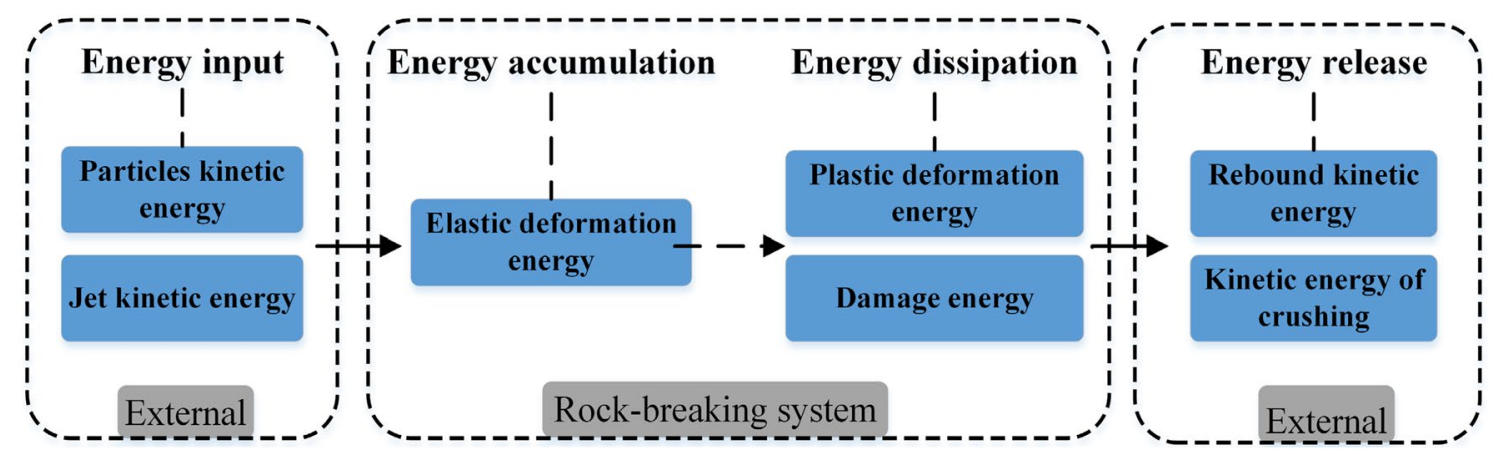

Fig. 11 Energy conversion process under particle jet impact

optimal well trajectory in directional drilling (Abdideh and Dastyaft 2021). Li et al. analyzed the rock-breaking process of inclined particle jet and water jet and proposed that large-area crushing is caused with combined action of direct impact and radial tension ( $\mathrm{Li}$ et al. 2020c). Based on the SPH-FEM method, the damage evolution process of rock under particles jet impact was simulated in our previous researches (Ren et al. 2020), and the damage process presented the cycle process of "damage-cumulative damage-failure-cumulative damage-failure", and rock failure is mainly represented shear macro fracture and tensile crack (Fig. 12). Next, the coupling analysis of confining pressure and temperature will be considered to further investigate the failure process under particle jet impact.

At present, the rock-breaking theory of vibration, hydraulic-mechanical joint and stress wave still need to be further investigated in field of particle jet impact drilling. Furthermore, the dynamic failure mechanism of deepwell rock under particle jet impact is likely to need to be revealed with guidance of a variety of theories, which is also the core research to be carried out.

\section{Research analysis and development direction of particle jet impact drilling}

\section{Research of advantages and disadvantages}

At present, many researches on the rock-breaking mechanism and technology development of particle jet impact drilling have been carried out. The simulation experiment and engineering application showed that the drilling technology has significant effect on overcoming the problem of slow drilling in deep wells and hard rock, which proves it has great development and application potential. Rock-breaking effect of particle jet impact drilling technology is equivalent to high-frequency erosion effect of metal particles superimposed on the basis of the rotary drilling effect of conventional bit and impact effect of high-pressure waterjet, and its main advantages include:

(1) Without changing the existing drilling equipment and drilling technology, by connecting particle injection device and drilling bit, it not only maintenances the advantages of rotating bit and high-pressure water jet,

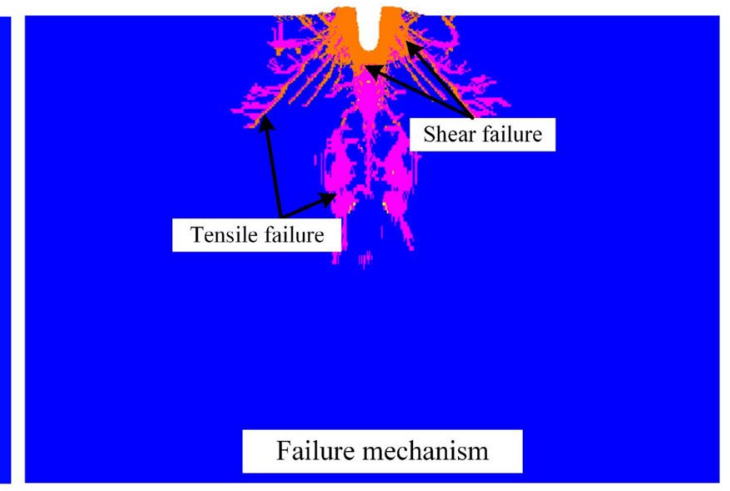

Fig. 12 Particle jet impact rock-breaking mechanism
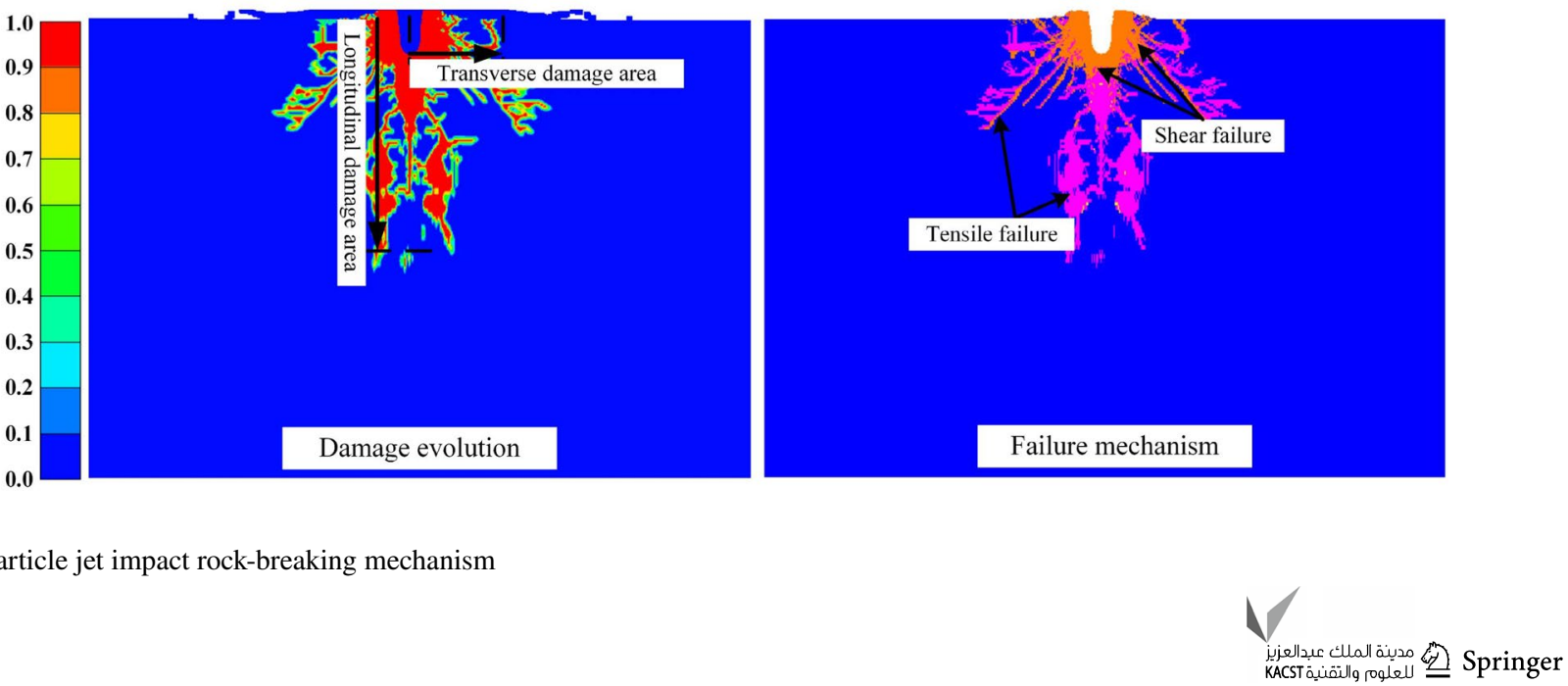
but also integrates the efficient impact of metal particles, and the rock-breaking effect is remarkable;

(2) Low WOB (weight of bit), prolong the service life of equipment, reduce the down-hole accident frequency and shorten drilling cycle;

(3) Less torque required, weaken the swing and fatigue damage of drill string, and prevent effectively well deviation;

(4) Low rock-breaking threshold stress under high-speed particles impact, accelerate drilling speed, and save cost.

Meanwhile, there are still some problems in the process of engineering application and industrialization of particle impact drilling technology, which mainly including:

(1) The complexity of drilling system leads to the excessive volume of apparatus and aggravation of pipeline wear, which would increase additional maintenance tasks;

(2) The down-hole environment is quite complex and changeable, and the real-time measurement of rock mechanical properties and constitutive model parameters is difficult. Therefore, the existing rock-breaking theory cannot fully reveal failure mechanism with particles-waterjet-mechanical action.

\section{Limitation analysis and prospective development direction}

There may be some possible limitations in this study, which is mainly due to the variability of down-well environment and the random distribution of particles:

(1) The evaluation method of rock-breaking effect under particle jet impact is mainly established through indoor simulation experiment, which is different from engineering field to a certain extent. Therefore, the evaluation method of rock breaking effect with underground environment needs to be constructed next.

(2) The analysis of rock-breaking mechanism is based on the uniform impact of particles, in fact, the mixing of water and particles cannot reach the ideal uniform distribution state. Therefore, the kinetic energy loss is inevitable in particles acceleration process, which resulting in a certain error between experimental results and theoretical analysis.

According to the above summary research, although great achievements have been made in research of particle jet impact drilling at home and abroad, further research on rockbreaking mechanism and drilling optimization are urgently needed before the technology is mature and applied:
(1) Miniaturization of drilling device and personalization of special PID bit. The miniaturization method of particle jet impact drilling device is to realize selfcirculation of downhole. Therefore, it is important to explore the optimal particle ratio and realize the accurate control of particle mixing system. Meanwhile, it is also important to simulate the wear rate and reliability of self-circulation device. PID bit is not only related to the acceleration effect of particle jet, but also the distribution of its nozzle has an important influence on drilling speed. Therefore, the flow characteristics of particle and waterjet of PID bit with state of rotating nozzle need to be investigated the optimal nozzle layout, drill tooth configuration, target distance and bit structure size, so as to realize high efficiency and personalization of PID bit, which is an important research content next research.

(2) Optimization of jet parameters and evaluation of rockbreaking effect. The important sign of field application of particle jet impact drilling technology is the parameters optimization and the evaluation of rock-breaking effect. For different bottom-hole environment, dynamical optimization of impact velocity, particle size and particle ratio need be realized. According to optimization effect, the establishment of mathematical model to evaluate rock-breaking effect will be an important research direction.

(3) Mechanical properties of deep-well rock and construction of unconventional constitutive model. Due to the environment of high pressure, high temperature and high geo-stress, not only rock strength and strain will be affected by confining pressure, but also elastic model will change with well depth. Therefore, based on the current logging data and simulation experiments, combined with deep-well fidelity coring technology, the mechanical properties of rock in deep well environment need to be investigated, and the constitutive model of rock elastoplastic mechanics also need to be constructed.

(4) Rock-breaking mechanism and dynamic response under particle jet impact. The damage of hard rock is actually a complex nonlinear dynamical response among particles, jet, bit and rock. In rock-breaking process, due to high frequency and small-contact-surface characteristics of particle impact, combined with resonance, stress wave and joint rock-breaking theory, dynamic response mechanism of rock with high pressure and high temperature under the action of particle-jet-drill tooth is also the next core research content. 


\section{Summary and conclusions}

1. As an efficient rock-breaking method to overcome the slow drilling speed in deep hard formation, particle jet impact drilling technology had been proved to significantly improve drilling velocity and rock breaking efficiency with relevant simulation experiments and field application. And the deep complex oil and gas resources status was investigated, and the key technologies of particle jet impact drilling were summarized, including particle mixing system, particle acceleration system, particle recovery system.

2. The research progress of particle jet impact drilling equipment, rock mechanics characteristics and rockbreaking mechanism in deep wells was overviewed and studied, which indicated the potential of particle jet impact drilling technology and the urgency of basic research on rock breaking theory. Besides, the existing problems of this technology were also put forward, such as the complexity of drilling system, the simplification of PID bit, the idealization of rock properties with high temperature and high pressure environment and the multi-field coupling of rock-breaking mechanism.

3. The advantages and disadvantages of particle jet impact drilling speed-increasing technology were analyzed, and research direction was also put forward, including: miniaturization of drilling device and personalization of special PID bit; optimization of jet parameters and evaluation of rock-breaking effect; mechanical properties of deep-well rock and construction of unconventional constitutive model; rock-breaking mechanism and dynamic damage response under particle jet impact.

Based on the review and research of particle jet impact drilling technology and the previous theoretical research of our research group, the application of particle jet impact drilling speed-increasing technology in the hard formation of deep and ultra-deep wells can greatly improve drilling efficiency and reduce drilling cost. Therefore, the fundamental research on rock-breaking mechanism under particle jet impact and tackle the key technologies can provide theoretical support for the development and engineering application of this technology and is of great significance to promote the development of deep and ultra-deep drilling technology and equipment.

Authors' contributions All authors contributed to the study conception and design. All authors read and approved the final manuscript. Fushen Ren had the idea for the article, Tiancheng Fang performed the literature search and data analysis, and Hanxu Liu, Yuan Zhang, and Jianxun Cheng examined the form of this work. Fushen Ren and Tiancheng Fang revised the article. All authors commented on previous and revision versions of the manuscript.
Funding This study was funded by National Natural Science Foundation of China (11972113), the Guiding Innovation Fund Project of Northeast Petroleum University (2019YDL-07).

Availability of data and material All data and material of this study are included in the article.

Code availability Not applicable.

\section{Declarations}

Conflicts of interest The authors declare that they have no conflicts of interest to report regarding the present study.

Open Access This article is licensed under a Creative Commons Attribution 4.0 International License, which permits use, sharing, adaptation, distribution and reproduction in any medium or format, as long as you give appropriate credit to the original author(s) and the source, provide a link to the Creative Commons licence, and indicate if changes were made. The images or other third party material in this article are included in the article's Creative Commons licence, unless indicated otherwise in a credit line to the material. If material is not included in the article's Creative Commons licence and your intended use is not permitted by statutory regulation or exceeds the permitted use, you will need to obtain permission directly from the copyright holder. To view a copy of this licence, visit http://creativecommons.org/licenses/by/4.0/.

\section{References}

Abdelghany WK, Radwan AE, Elkhawaga MA, Wood D, Sen S, Kassem AA (2021) Geomechanical modeling using the depthof-damage approach to achieve successful underbalanced drilling in the Gulf of Suez Rift Basin. J Petrol Sci Eng 202:108311

Abdideh M, Dastyaft F (2021) Stress field analysis and its effect on selection of optimal well trajectory in directional drilling (case study: southwest of Iran). J Petrol Explor Prod Technol 144. https://doi.org/10.1007/s13202-021-01337-5

Cheng X, Ren F, Fang T, Chang Y (2018) Rock breaking experiment by particle jet coupling impact. Acta Petrolei Sinica 39(02):232-239

Geng Q, Wei Z, Ren J (2017) New rock material definition strategy for fem simulation of the rock cutting process by tbm disc cutters. Tunn Undergr Sp Tech 65:179-186

Guo Z, Deng R (2021) Research on tooth wear of non-spherical single-cone bit in hard rock formation of deep well. Eng Fail Anal 125(8): 105408

Huang F, Hu B, Zuo W, Li S et al (2019) Experimental study on impact characteristics of high pressure water jet with different nozzle shapes. J Chongqing Univ 42(09):124-133

Jia CZ, Pang XQ, Jiang FJ (2016) Research status and development directions of hydrocarbon resources in China. Petrol Sci Bull $1(01): 2-23$

Jiang H, Zhao H, Gao K, Wang O, Wang Y, Meng D (2020) Numerical investigation of hard rock breakage by high-pressure water jet assisted indenter impact using the coupled $\mathrm{sph} / \mathrm{fem}$ method. Powder Technol 376:176-186

Jiang Y, Xie YG, Shen P, Yang Q, Zou Y, Qin X, He Q (2020) Study on mechanical properties and constitutive equations of sandstone. China Coal 46(10):87-91

Kassem AA, Sen S, Radwan AE, Abdelghany WK, Abioui M (2021) Effect of depletion and fluid injection in the mesozoic and paleozoic sandstone reservoirs of the october oil field, central gulf

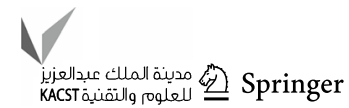


of suez basin: implications on drilling, production and reservoir stability. Nat Resour Res 30(3):2587-2606

Kovalyov, A. V., Ryabchikov, S. Y., Isaev, Y. D., Aliev, F. R., Gorbenko, M. V., Baranova, A. V. (2015). Pellet impact drilling operational parameters: experimental research. In: IOP Conference 24: 012015.

Li L, Wang F, Li T, Dai X, Yang X (2020c) The effects of inclined particle water jet on rock failure mechanism: experimental and numerical study. J Petrol Sci Eng 185:106639

Li S, Ma S, Han R (2012) Application of smooth drill collars with high WOB deviation control technology in Xujiaweizi area. Sci Technol Eng 12(4):766-769

Li J, Xing X, Li S, Cai C, Li Q (2014) Design and research of rotary vane particle drilling injection device. China Petrol Mach 42(08):37-40

Li Y, Xue Z, Cheng Z, Jiang H, Wang R (2020a) Progress and development direction of deep oil and gas exploration in China. China Petrol Explorat 25(1):45-57

Li S, Tian S, Li W et al (2020b) Numerical study on the elastic deformation and the stress field of brittle rocks under harmonic dynamic Load. Energies 13(4):1-16

Liu Y, Wei J, Ren T (2016) Analysis of the stress wave effect during rock breakage by pulsating jets. Rock Mech Rock Eng 49(2):503-514

Liu Y, Chen CJ, Liu XT et al (2017) Mechanism on energy dissipation and release of rock breakage with high pressure water jets. J China Coal Soc 42(10):2609-2615

Perzyna P (1966) Fundamental problems in viscoplasticity. Adv Appl Mech 9(2):243-377

Rach NM (2007) Particle-impact drilling blasts away hard rock. Oil Gas J 105(6):43-48

Radwan AE, Sen S (2021) Characterization of in-situ stresses and its implications for production and reservoir stability in the depleted El Morgan hydrocarbon field, Gulf of Suez Rift Basin, Egypt. J Struct Geol 148:104355

Radwan A, Sen S (2021a) Stress path analysis for characterization of in situ stress state and effect of reservoir depletion on present-day stress magnitudes: reservoir geomechanical Modeling in the Gulf of Suez Rift Basin. Egypt Nat Resour Res 30:463-478

Radwan AE, Abdelghany WK, Elkhawaga MA (2021) Present-day insitu stresses in Southern Gulf of Suez, Egypt: Insights for stress rotation in an extensional rift basin. J Struct Geol, 104334.

Radwan, AE, Sen S (2021) Stress Path Analysis of the Depleted Miocene Clastic Reservoirs in the El Morgan Oil Field, Offshore Egypt. In: 55th US Rock Mechanics/Geomechanics Symposium.

Ren F, Fang T, Cheng X (2019) Theoretical modeling and experimental study of rock-breaking depth in particle jet impact drilling process. J Petrol Sci Eng 183:106419

Ren F, Fang T, Cheng X (2020) Study on rock damage and failure depth under particle water-jet coupling impact. Int J Impact Eng 139:103504

Ren F, Cheng X, Li Y et al (2017) Modeling and experimental analysis of particle jet coupled impact rock fracture. Eng Mech 34(02):255-262

Su Y, Lu B, Liu Y, Zhou Y, Liu X, Liu W, Zang Y (2020) Status and research suggestions on the drilling and completion technologies for onshore deep and ultra-deep wells in China. Oil Drill Prod Technol 11:1-24

Tang L, Zhu X (2018) On the development of high-frequency torsional impact drilling techniques for hard formation drilling. Adv Mech Eng 10(6):1-15

Thomas H (2007) Particle drilling pulverizes hard rocks. Am Oil Gas Report 50(7):86-89

Tian JL, Fu CH, Pang XL, Yang L (2016) Study on the influence of high frequency torsional vibration on rock breaking characteristics during drilling. Chin J Appl Mech 33(05):792-798
Tibbitts, G. A., Padgett, P. O., Curlett, H. B. (2007). Drill bit: US, 7258176.

Xu C, Zhou W, Yang Y, Yong D, Zhang J (2018) Status and prospects of exploration and exploitation of the deep oil \& gas resources onshore China. Nat Gas Geosci 28(08):1139-1153

Tibbitts, G. A. (2008). Impact excavation system and method with suspension flow control: US, 758176B2.

Wang H, Ge Y, Shi L (2017a) Technologies in deep and ultra-deep well drilling: present status, challenges and future trend in the 13th Five-Year Plan period (2016-2020). Nat Gas Ind 4(5):319-326

Wang F, Wang R, Zhou W (2017b) The influencing factors of the rock breaking effect under particle water jet impacting. Petrol Drill Techn 45(02):40-45

Wang JF (2020) Development and field test of particle impact bit. West-China Explorat Eng 32(06):113-116

Wang R, Wang F, Zhou W (2016) Particle impact drilling technology: the state of the art and perspective development. J China Univ Petrol (edition Natural Sci) 40(06):71-79

Wu K, Rong M, Li D, Kuang Y, Luo J (2009) Simulation study of impacting breaking rock by double particles. Rock Soil Mech 30(z1):19-23

Xi B, Zhao Y (2010) Experimental study of thermophysico-mechanical property of drilling surrounding rock in granite under high temperature and high pressure. Chin J Rock Mech Eng 29(06):1245-1253

Xu Y, Mao B, Zhao J (2012) Principle analysis and structure design of particle grading device in practice impact drilling. Drill Prod Technol 35(03):18-21

Xu Y, Liao K, Jin J, Liu Q, Sun Y (2013) Design of the double plunger for particle impact drilling injection system. China Petrol Mach 41(03):7-10

Yao J, Huang Z, Liu W, Zhang Y, Zeng Q, Xia Y (2018) Key mechanical problems in the development of deep oil and gas reservoirs. Sci Sin Phys Mechan Astronom 48(04):5-31

Yang M, Yang Y, Bian W, Wu J (2021) Drilling progress and technological improvement of ultradeep wells in Russia. Oil Drilling \& Production Technology 43(1):15-20

Zhang, Y., Zhao, H., Wu, Z., Wen, L., Zhou, F. (2009). Particle impact drilling method and device, CN 102022078A.

Zhang J, Niu X, Zhang J (2015) Research and industrial application of drilling technology of ultra-deep wells. Explorat Eng (rock Soil Drilling Tunnel) 42(01):3-11

Zhao Y, Gou X (2020) A brittleness evaluation method based on breaking energy theory for tight reservoir in Dagang Oilfield. J Petrol Explor Prod Technol 10:1689-1698

Zhao J, Han L, Xu Y, Jin J, Liu F (2014) A theoretical study and field test of the particle impact drilling technology. Nat Gas Ind 34(08):102-107

Zhou Y, Xing XY, Wang RY, Wang R, Li J, Li Q (2014) Design and test of rotating particle recovery tank system for particle impact drilling. China Petrol Mach 42(09):31-34

Zhao C (2016) Numerical simulation of PID bit bottom hole flow field and research on bit design. China University of Petroleum (East China), Qingdao

Zhu X, Luo Y, Liu W (2020) On the rock-breaking mechanism of plasma channel drilling technology. J Petrol Sci Eng 194:107356

Zhu XH, Liu WJ (2018) Rock breaking and ROP rising mechanism of rotary-percussive drilling technology. Acta Petrolei Sinica 39(02):216-222

Publisher's Note Springer Nature remains neutral with regard to jurisdictional claims in published maps and institutional affiliations. 